\title{
Translation of Automobile Brand Name From the Perspective of Skopostheorie
}

\author{
ZHANG Guang-qi \\ Beijing Information Science \& Technology University, Beijing, China
}

\begin{abstract}
The brand name, embracing specific culture of enterprises and information of products, has a plentiful symbolic meaning and a significant effect on commercial marketing and purchaser's recognition. Over the past years, many scholars have made extensive explorations in the field of brand name translation from different perspectives. While there are still some deficiencies in the practical application, this paper attempts to construct a theoretical framework for the translation model on the basis of Skoposthorie. Translation is not only an action, but a purposeful activity. It is important that translators should feasibly choose different translation methods owing to the target function and purpose, culture diversity and psychology of consumers who are also the target receivers. Thus, the author proposes four translation methods for automobile brand name translation under the guidance of Skopostheorie, and three translation principles through quantitative analysis.
\end{abstract}

Keywords: Skopostheorie, quantitative analysis, translation method, translation principle

\section{Introduction}

In modem society, the brand name, as a commercial concept, is an efficient component for advertisement and promotion, and plays an important role in business competition. The global companies have realized the importance of good brand names in the process of advertising products, stimulating purchase, and developing new markets. Therefore, in order to gain great success worldwide, it is urgent for these enterprises to translate automobile brand names well.

As we know, the comprehensive studies in the field of brand name translation have been made by some scholars from different perspectives. The translation theories of all these findings are almost based on YAN fu's (1984) “faithfulness”, “expressiveness”, and “elegance”, Nida’s (2001) “equivalence”, or Newmark’s (2004) "semantic translation", which cannot help serving the purpose of brand name translation in practical application. The purpose of translation is very clear, to stimulate the sales and gain commercial interests to the utmost. Here, Skopostheorie regarding the purpose and aim of translation as dominant translation brief should a new perspective to be the guide.

\section{Basic Concepts of Skopostheorie}

\section{Skopos}

Skopos is a Greek word for "purpose”. According to Skopostheorie, the prime principle determining any

ZHANG Guang-qi, associate professor, School of Foreign Studies, Beijing Information Science \& Technology University. 
translation process is the purpose (Skopos) of the overall translation action (Nord, 2001, p. 27).

In the field of translation, there are three possible kinds of purpose: the general purpose aimed at by the translation process (perhaps "to earn a living"), the communicative purpose aimed at by the target text in the target situation (perhaps "to instruct the reader"), and the purpose aimed by a particular translation strategy or procedure (for example, "to translate literally in order to show the structural particularities of the source language”) (Vermeer, 1989, p. 100). The term Skopos, however, usually refers to the purpose of the target text.

Apart from the term Skopos, Vermeer uses the related words-aim, purpose, intention, and function. "Aim” is the final result which an agent intends to achieve by an action; "purpose" is a provisional stage in the process of attaining an aim; "function" refers to what a text means or is intended to mean from the receiver's point of view; while "intention" is conceived as "an aim-oriented plan of action" on the part of both the sender and the receiver, pointing toward an appropriate way of producing or understanding the text (Nord, 2001, p. 28). These four concepts are very confusing and thus sometimes are considered equivalent. As a matter of fact, they are not identical. "Intention" is defined from the viewpoint of the sender, while "function" is from that of the receiver. An action has an "aim”, while a translation text has "purposes".

\section{Three Rules of Skopostheorie}

Skops rule. The central and primary idea of Skopostheorie is that "the translation purpose justifies the translating procedures" and it is generally expressed as "the end justifies the means" (Nord, 2001, p. 29). Therefore, in Skopostheorie, the top-ranking rule that any translation should observe is the "Skopos rule". According to the Skopos rule, the translator must do translation in accordance with some principles respecting the target text by adapting to the addressee's background knowledge, expectations, and communicative needs, since the reader, or rather, the addressee, is the main factor determining the Skopos.

Coherence rule. The coherence rule specifies that a translation should be acceptable in a sense that it is coherent with the receivers' situation (Reiss \& Vermeer, 1984, p. 113). Being “coherent with” is synonymous with being "part of" the receiver's situation. The starting point for a translation is a text as part of a world continuum written in the source language. In other words, the target text must be translated in such a way that it is coherent for the target text receivers, given their circumstances and knowledge (Munday, 2001, p. 79).

Fidelity rule. Since a translation is an offer of information about a preceding offer of information, it is expected to bear some kind of relationship with the corresponding source text (Nord, 2001, p. 32). Fidelity rule merely states that there must be coherence between the translation and the source or, more specifically, between: the source text information received by the translator; the interpretation the translator makes of this information; and the information that is encoded for the target text receivers (Munday, 2001, pp. 79-80).

The important point is that the translated text must be loyal to its corresponding source text in a certain level of features, including special collocations, sentence length, grammatical features, or even rhetorical devices, in style, in function, and so on, or to a certain extent between a complete imitation and a complete deviation. It is the translator's task to decide the aspect and the extent of the fidelity, according to his own understanding of the source text and the translation Skopos.

\section{Automobile Brand Name}

A brand name, as a marketing concept, is no longer a mark to register the producer or seller; it is a trigger to 
win the market (Hankinson \& Cowking, 1993, p. 4). Therefore, only when we completely know brand name, can we choose the suitable strategy for its translation.

\section{Origins of Brand Names}

To translate the automobile brand names well, the translators should at first have an idea of naming of various brand names closely related to culture. The origins of these brand names differ in the following aspects.

From historic person's names. Many automobile brand names are named after names with certain historic meanings, such as the great names of history, or the great contributors from all walks of life, such brand names are not only memorable but also enrich the cultural foundation of automobiles (see Examples 1-4):

Example (1) "Benz" is used in memory of Carl Friedrich Benz, one of German automobile pioneers who built the world's first automobile powered by an internal combustion engine. Later, the Benz automobile company and Daimler (another German automobile company) merged in 1926 to form the Daimler-Benz company, which marked their products under the Mercedes-Benz nameplate.

Example (2) "Cadillac" is to honor Antonio Cadillac, a French colonial governor in North America and founder of the automobile city, Detroit (The Cadillac automobile company was founded during the bicentennial celebration of the founding of Detroit).

Example (3) "Chevrolet” is named in memory of a Swiss American automobile designer and racer, Louis Chevrolet who designed his first car in 1911, under the sponsorship of William C. Durant, founder of the GM (General Motors) Corporation. And Durant formed the Chevrolet Motor Company in 1911 by getting Chevrolet's interest in that car.

Example (4) "Lincoln” got its name from American president Abraham Lincoln. Lincoln cars are super sedans specially produced for presidents and heads of state.

More examples are given in the following: Daimler 戴姆勒 (British, Gofred Daimler), Datsun 达桑特 (Japanese, Den, Aoyama, Takeuhi), ERF (American, the abbreviation of Edwin Richard Foden), Lancia 兰西亚 (Italian, Wensonz Lancia), Porsche 波尔希 (German, Ferry Porsche), and so on.

From the names of objects. (1) Animal names. “Beetle” car (甲壳虫) made by Volkswagen gets its name from beetles, a kind of very small insects. So does the British "Jaguar”. Jaguar is a large South America wild cat and runs very quickly. "Jaguar” is translated into “捷豹” indicating the speediness of this car. Automobile manufacturers use animal's names as their brand names in the hope of complimenting their cars. See more examples: Bear (白熊), Blackhawk (黑鹰), Bronco (烈马), Firebird (火乌), Lion (雄狮), Mastiff (猛犬), Maverick (野牛), Pinto (瑰正马), Sable (貂), Sambar (大鹿), and Topaz (蜂乌).

(2) Airplane names. For example: Skyliner (航空班机), Spaceliner (航天班机), Aero King (空中之王), Space Wagon (太空车), Jetliner (喷气飞机), Aeorstar (航空之星), Clubliner (俱乐部班机), and Soarer (滑 翔机).

(3) Astronomical names. Such as Arise (白羊座), Galaxy (银河), Orion (猎户座), Telstar (通信卫星), Vega (织女星), Subaru (星宿集团), and Zodiac (黄道带).

(4) Flower or tree names. See the examples: Aspen (白杨), Corolla (花冠), Lotus (莲花), and Violet (紫 罗兰). 
From the names of natural phenomena. German Volkswagen automobile company likes naming their cars from wind names. "Santana” is a valley name in California and it often blows gusts of typhoon called “Santana” by local people. Volkswagen Santana is a car named after the wind. “Passat” (帕萨特), “Bora” (宝 莱), “Scirocco” (海风), and “Jetta” (捷达) also get their names from the wind. More examples are given: “Tempest” (暴风雨), “Stratus” (云彩), “Blizzard” (暴风雪), “Rainbow” (彩虹), and “Aurora” (奥罗拉), originally means “北极光, 南极光”).

From common words. Some common words are used as automobile brand names. These words always sound positive, bear beautiful meanings and features of the cars. For example, "Regal”, cars of GM company, means “君主” and “皇家” and represents the noble status of the owners. “Saxo” (萨克斯), the car, produced by Citroen automobile company, associates the consumers with the pure beautiful music played by saxophone. See more examples: Celebrity (名人), Continent (大陆), Crown (皇冠), Alliance (同盟), Accord (和谐), Triumph (胜利), Legend (传奇), Sunny (阳光), and Dynasty (王朝).

Fabricated names. Considering such aspects as corporate culture, social culture, and market demand, automobile companies create brand names in order to promote their cars by applying the knowledge of psychology, aesthetics, and linguistics. “Excelle” (凯越) of Buick company is changed from the word “excellent”. There are more innovative words as automobile brand names, such as, “Elantra” (伊兰特), “Lioncel” (菱帅), “Range Rover” (路虎), “Acura” (讴歌), and “Elise” (爱丽丝).

\section{Functions of Automobile Brand Name}

Language has to serve various purposes due to different types of occasions. The usage of language is reduced to different functions. The brand name is the core of a product's identity and personality. In the competitive market, a memorable and successful brand name is of vital importance in creating and sustaining product image and positioning.

Distinctive function. There are a number of different specifications, qualities, and colors of the same kind of goods. It is necessary for producers to adopt special band names to differentiate the same kind of commodities (LIANG, 1998). Brands, as the windows of the products, enable the consumers to recognize a certain product and help the producers to differentiate their own products from the same kinds of goods produced by competitors. For example, “Ford”, “Mazda”, “Volvo”, “Audi”, “Chevrolet”, “Daimler”, etc., are different brand names of automobiles, which help the consumers distinguish one product from another.

Informative function. As is well known to everybody, high information is an important value of advertisement. Brand names, as a kind of advertisement, should provide the consumers with as much information as possible, such as, the information about characteristics, functions, target consumers, and so forth.

Firstly, some brand names imply the characteristics and functions of the products. For example, "Ettore Bugatti 110 (EB 110 for short) and “EB 118” have special meanings respectively. Ettore Bugatti (埃托雷·布加 迪) is the founder of EB automobile company. In celebration of his 110-year-old birthday, EB 110 is named. In "EB 118”, the first number " 1 ” here means the first one in the world; and "18” indicates that this type of automobile has 18 cylinders. On the whole, the company intends to tell the consumers that this is the first super sports car with 18 cylinders in the world. “Jatta” (捷达) and “Passat” (帕萨特) are named after the local tornadoes in America, signifying rapidity of their cars. 
Secondly, some brand names convey connotations of the naming. "Rolls-Royce” (劳斯莱斯) indicates the founders of the car company, Charles Rolls and Henry Royce. "Bluebird” (蓝鸟) is the band name of a Japanese automobile company. Here "bluebird”, which symbolizes "happy future”, is quoted from the pantomime "Bluebird” written by a Belgian writer, Maurice Materlinek in 1911. As an automobile brand name, "bluebird" means "the origin of happiness".

Thirdly, brand names can also indicate information about the owners, such as taste and status. "Cherry QQ (奇瑞 QQ)”, “Smart”(精灵), “MINI Cooper” (迷你 Cooper), and “Beetle” (甲壳虫) are all appealing to women, because these words cater to women’s psychology, i.e., cute, beautiful, and elegant. While "Silver Ghost” (银雾), “Phantom” (魅影) of Rolls-Royce, “Bentley Arnage R” (宾利·雅致R), “Bentley GT”, and “Bentley Hunaudieres”, etc., are all the names of the world high-class automobiles symbolizing identity and dignity.

Vocative function. Vocative function means that brand names should arouse consumers' interest in the products and persuade them to make a purchase. Good brand names are the most direct and effective way of advertising and they can go deeply into every consumer's heart. Therefore, the function of brand names in promoting products should be stressed. "This inducing function can attract the consumers' great attention in order to assure the consumers of purchasing products. Therefore, all these features that the brand name possesses are called the function of advertising” (WU \& CAO, 2005, p. 7).

This vocative function can be realized in many ways. Some automobiles brands are named after the famous persons, such as "Chevrolet” (from Louis Chevrolet), "Ford” (Henry Ford), "Benz” (Karl Benz), "Chrysler" (from Walt Purcy Chrysler), and "Ferrari” (from Enzo Ferrari) and so on. This is because the consumers worship the celebrities and have the psychology of imitating them. Besides, some brand names inform people about the value of the products. For example, “Crown” (皇冠) and “Eldorado” (黄金之国) both indicate the value of being superior and noble.

\section{Translation of ABN (Automobile Brand Name)}

\section{Significance of Skopostheorie Applied to ABN Translation}

Skopostheorie, on the one hand, provides translation practice with a general theoretical framework, directs the translator to lay more emphasis on the translation function instead of the limited scope of equivalence between the source and target texts. In functionalist approach to translation, the target addressee is assigned a higher status and a more influential role.

On the other hand, Skopostheorie provides the translator with the practical and feasible operational rules, namely, Skopos rule, coherence rule, and fidelity rule, which can be used in the whole process of translation, including the decision-making and problem-solving process.

The translator should be able to justify their choice of a particular Skopos in a given translation situation. The translation purpose (Skopos) defined by the translation brief which is a part of the translation commission given by the initiators, specifies what kind of translation is needed for the translator.

\section{Translation of ABN in the Light of Skopostheorie}

The following is a close combination of the basic concepts of Skopostheorie with practical translation of automobile brand names.

Skopos of ABN translation. According to Skopostherie, the prime principle determining any translation 
process is the purpose (Skopos) of the overall translational action (Nord, 2001, p. 27). To achieve the Skopos, we should adopt various translation strategies, which is just the essence of Skopoetheorie, namely, "the end justifies the means". And the ultimate goal of the automobile companies establishing brand names is to promote the sales of their products. Based on the functions of brand names, it is clear that automobile brand name translation should bear two purposes: (1) general purpose, to set up good images of products and enterprises in the target marketplace and consumers' acceptance of them; and (2) ultimate purpose, to act as a means of promotion, aiming at striking a sympathetic response among target consumers and promoting the sales of the products.

Translation brief of ABN. According to Skopostheorie, every translation process accompanies a translation brief. "A good brief usually spells a better translation” (Nord, 2001, p. 30). An analysis of the translation brief of automobile brand names is as follows: (1) intended text function: distinctive function, informative function, and vocative function; (2) target-text addressee: potential consumers, who intend to purchase products or service; (3) place of text reception: appear on any publication available, like magazines, newspapers or TV programs, the Internet, and automobile shopping centers when the products go on sale or brand-new products come into the market; (4) medium over which the text will be transmitted: automobile magazines, sales brochures, pamphlets or leaflets, and advertisements (both written language and videos); and (5) motive for the production or reception of the text: to familiarize the audience with the brands, to establish good enterprise image, and to appeal to potential consumers, to promote the products.

Since every translation task is accompanied by a translation brief, it is of great importance for the translators to bear in mind the above translation brief when translating automobile brand names.

Factors to be considered in ABN translation. The translation of brand names is a kind of intercultural communication, which involves regional cultures, consumer psychology, aesthetic interest, and some other factors. Thus, the translator should take into account such factors as the intended functions of target texts, cultural diversity, and consumer psychology in the process of automobile brand name translation from the perspective of Skopostheorie.

Intended functions of target texts. The intended text function refers to functions the target text will perform in the target text environment. In order to make clear the intended function of the target text, the translator should be familiar with the Skopos of the target text. In other words, it is of importance for the translator to figure out the Skopos of the target text during translation under the guidance of Skopostheorie. Moreover, "every translation task should be accompanied by a brief that defines the conditions under which the target text should carry out its particular function” (Nord, 2001, p. 59).

Some Japanese automobiles are named from borrowing words, such as “Crown”, “Ballade”, and "Leon”. So as to promote the sales of these cars in China's marketplace, when translating brand names translators apply different translation methods according to different intended functions of target texts. To reflect the characteristic of luxury of “Crown”, it is translated into “皇冠” (1iteral translation). “Ballade”, a French word is translated into “叙事曲” (1iteral translation), which associates the consumers with the romance of France to stress its characteristics of elegance and dignity. "Leon" is an Italian word and a kind of sports car, thus it is translated into “利昂” (transliteration), reminding the consumers of the world-class sports cars in Italy, such as “Ferrari” (法拉利). 
Cultural diversity. A brand name comes from a certain language, as a result, it must bear some traits of the culture it belongs to. For Nord, "translating means comparing cultures”, i.e., translation is a communicative action that takes place between cultures. Therefore, the translation of automobile brand name is a kind of communication across cultures rather than a mechanical language transfer.

To cross the cultural barriers, the translator should be familiar with the target culture, and make flexible adaptations to get the target audience well understand and accept the translated brand names; otherwise, misunderstanding and negative effects may be brought about. For example: Rolls-Royce automobile company tried to sell their "Silver Mist" (银雾) model in Germany, but did not achieve the intended goal, because "Silver Mist” comes out as “Silver Animal Droppings” (排泄物) in German. GM Corp. renamed "Buick LaCrosse” in Canada, because the name was a slang for "masturbation" in Quebec. The automaker was not aware that "LaCrosse" was a term for self-gratification among teenagers in French-speaking Quebec.

Consumer psychology. According to Nord (2001, p. 21), the intended target-text receiver is the addressee of the translation and is thus a decisive factor in the production of the target text. Therefore, consumers are the target addressee of the translation and translation of automobile brand name is inevitably consumer-oriented.

However, different ideological backgrounds give rise to different consuming psychologies. Delighted or hatred, joy or displeasure, and acceptation or rejection, these are all critical psychological elements to be placed emphasis on, for the consumer's psychology in a sense can determine the further development of an enterprise in the target market (CHEN, 2004). In other words, to both marketers and translators, the possession and mastery of the information relevant to consumer psychology is of great significance.

As we know, "BMW" is an acronym for "Bayerische Motoren Werke” (Bavarian Motor Works in English), the German mobile manufacturer in Munich. "BMW" is also the brand name for plane engines, cross-country vehicles, motorcycles, and the first-class cars the company produces. Since the source brand name (BMW) is an acronym, it does not seem to convey any particular meaning. When the automobile enters Chinese market, the translator adapts linguistic selections to the consumers' purchasing psychology, i.e., their expectation to know the performance of the first-class car, and translates it into “宝马”. “宝” means “precious” and “马” (horse) indicates that the car is as speedy as a horse that could cover a thousand li a day in Chinese legend. Another famous car “Porsche” is translated into “保时捷”. “保时” keeps part of the original sound, while “捷” stresses the swift speed of the car. Other examples such as “Mazda” (马自达), “Cortina” (跑天下), and “Mustang” (野马), are all of this kind. These translated brand names all cater for the psychological needs of the target consumers and are proved to be successful in Chinese market.

Translation methods. The four translation methods are analyzed with detailed examples, namely, transliteration, literal translation, combination of transliteration and literal translation, and free translation under the guidance of Skopostheorie.

Transliteration. Transliteration means writing or spelling a word or sentence in the alphabet of a different language, which is mainly used to translate proper names from one language into another. In automobile brand name translation, transliteration is frequently adopted in order to keep the sound beauty of the original, thereby making it easier to disseminate orally, or to keep the exoticness of the original (see Example 5):
Example (5) Lamborghini一兰博基尼
Buick一别克
Santana一桑塔纳
Lincoln一林肯 


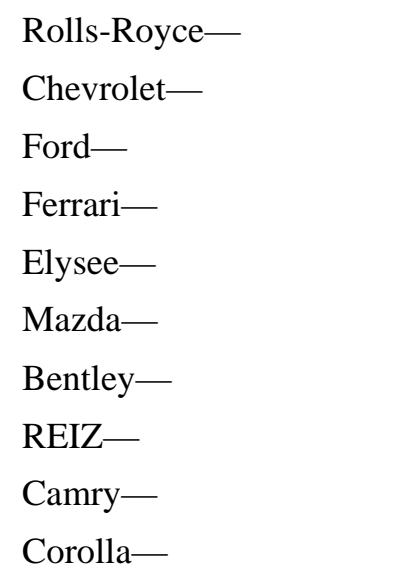

$$
\begin{aligned}
& \text { Cadillac一凯迪拉克 } \\
& \text { Chrysler一克莱斯勒 } \\
& \text { Volvo一沃尔沃 } \\
& \text { FIAT—菲亚特 } \\
& \text { Audi一奥迪 } \\
& \text { Sonata一索纳塔 } \\
& \text { Renault一雷诺 } \\
& \text { Passat一帕萨特 } \\
& \text { Prado一普拉多 } \\
& \text { Lexus一雷克萨斯 }
\end{aligned}
$$

Among them, “Audi”, “Buick”, “Chevrolet”, “Ford”, “Ferrari”, “Chrysler”, “Lamborghini”, “Renault”, and "Rolls-Royce” were named after the founders of the automobile companies that started making them. In memory of the founders, transliteration approach is the best choice. "Lincoln" gets its name from American president Lincoln. “林肯” associates Chinese consumers with “dignity” and “greatness”. “Santana” is the name of a valley where a strong cyclone always blows in Califomia, America. “马自达” indicates speediness of the car. “沃尔沃” conveys the beautiful sound of the brand name. “锐志” is the name with meaning attached on the sound” which has the same pronunciation with “睿智”.

Although transliteration is commonly used in automobile brand name translation, it still has its deficiencies. Transliteration cannot reveal much information about the products, and in some cases, the rational and emotional appealing message of the original can not be conveyed by pure transliteration. Thus some other translation methods are applied.

Literal translation. According to Newmark (2004, p. 70), in order to achieve translation equivalence, either in communicative or semantic translation, the method of literal translation is the basic transition procedure. This method, with its aim at retaining the national or local color, the original images as well as foreign expressions so as to enrich the target language, can keep the characteristics of the original and convey its exact original message and feelings directly and accurately.

For example, the car “Bluebird” is literally translated into “蓝鸟”. The translation keeps the flavor of the original (the car got its name from the book The Return of the Bluebird by Andre P. Dion) and associates the consumers with happiness and blessing.

Another very good example is “Beetle” which is literally translated into “甲壳虫”. It conveys the same message as the source text: The car looks like a beetle, a smart design that can allow for reliability, enjoyment, and vacation travel (see Example 6):
Example (6) Crown一皇冠
Regal一君威
Lotus一莲花
Golf一高尔夫
Swift一雨燕
Sunny一阳光
Landwind一陆风
Mustang一野马

Among them, “皇冠” and “君威” symbolize the noble status of the car owners.“雨燕”, “野马”, and “陆风” highlight the speed of the cars. “高尔夫” is associated people with a kind of recreation and indicates that the 
driver will enjoy unlimited driving pleasure. “阳光”, together with its sales advertisement: “Sunshine of life experience” (体验阳光生活), reveals the characteristics of elegatice and fashion. This car particularly appeals to young white-collar workers.

Combination of transliteration and literal translation. In order to make a brand name best perform its functions in the target language and realize the intended function on the addressee, we can combine the two approaches of transliteration and literal translation. As brand name translation is consumer-oriented, the combination of transliteration and literal translation can reflect the message of a brand name more vividly so that it will be more impressive to promote consumption and sales.

For example, the Chinese name for “Benz” (奔驰), created by the combination of transliteration and literal translation method, sounds similar to the original English name and also convey semantic, or meaningful information (see Example 7):

$$
\begin{aligned}
& \text { Example (7) City一思迪 } \\
& \text { Land Rover一路虎 } \\
& \text { Jaquar一捷豹 } \\
& \text { Legacy一力狮 } \\
& \text { Fit一飞度 } \\
& \text { Porsche一保时捷 } \\
& \text { Opel一欧宝 }
\end{aligned}
$$

Tiguan一途欢

New Santafe一新圣达菲
Citroen一雪铁龙
Hummer一悍马
Royaum一荣御
Jetta一捷达
Bora一宝来
Family一福美来
Touran一途安

Several names are transliterated into “虎”, “龙”, “豹”, “马”, and “狮” which stand for energetic and powerful images to attract customers. And Chinese producers always name their products with the words “福”, “富”, “贵”, etc., to symbolize good luck, happiness, or beauty. “福美来” is given local flavor by transliterating the letter “F”. “保时捷” and “捷达” perform the similar sound effect to the original brand names and embrace the meaning of high speed. In ancient China, “御” means royal and imperial and “荣御” indicates the status and dignity of the car owners. “途欢” and “途安” are intended to assure the consumers of a pleasant journey.

Free translation. Free translation is a strategy which should be used when the situation referred to in the source text does not exist in the target culture, or does not have the same relevance or connotations as it does in the source context. Under the guidance of Skopostheorie, source text is an offer of main information, translators can select the information they need to present in the target text. Free translation is used to create new information to inform the consumer of information of the products when other translation methods are incapable of conveying similar meanings to the addressee. In this way, the translated brand name is totally adapted to the typical target language.

For example, "Twingo", a very small and extremely successful car built by the French company Renault, got its name from the words “Twist”, "Swing”, and “Tango". "Twingo” can be literally translated into “两人 行” or “双人行”, but this translation is so common that it can not impress or appeal to the consumers. The translation “丽人行” associates the consumers with the joyride of a hero and a beauty, which stimulates consumers purchasing desire.

“LaCrosse” and “Excelle” are translated into “君越” and “凯越” respectively in which the translator 
successfully selects the target language culture to remind the target audience of a triumphant return, and also reflects image and feature of product. While “Accord” and “Stream” are translated into “雅阁” and “时韵” respectively, which are full of elegance and temperament.

Translation Skopos. In Skopostheorie, the primary rule for any translation is the Skopos rule, which holds that a translational action is determined by its Skopos. Translation Skopos justifies translation method. Based on 58 automobile brand names and the above-mentioned four translation methods, the author classifies every translation as a different translation principle according to different Skopos (see Table 1).

Table 1

Four Suggested Translation Principles

\begin{tabular}{|c|c|c|c|}
\hline Translation methods & English name & Chinese name & Translation principle \\
\hline \multirow{24}{*}{$\begin{array}{l}\text { Transliteration } \\
\text { (24) }\end{array}$} & Lamborghini & 兰博基尼 & A \\
\hline & Buick & 别克 & A \\
\hline & Santana & 桑塔纳 & A \\
\hline & \begin{tabular}{|l|} 
Lincoln \\
\end{tabular} & 林肯 & A \\
\hline & Rolls-Royce & 劳斯莱斯 & A \\
\hline & Cadillac & 凯迪拉克 & A \\
\hline & Chevrolet & 雪佛兰 & $\mathrm{A}$ \\
\hline & \begin{tabular}{|l|} 
Chrysler \\
\end{tabular} & 克莱斯勒 & A \\
\hline & Ford & 福特 & A \\
\hline & Volvo & 沃尔沃 & A \\
\hline & Ferrari & 法拉利 & A \\
\hline & FIAT & 菲亚特 & A \\
\hline & Elysee & 爱丽舍 & A \\
\hline & Audi & 奥迪 & A \\
\hline & Mazda & 马自达 & A \\
\hline & \begin{tabular}{|l|} 
Sonata \\
\end{tabular} & 索纳塔 & $\mathrm{A}$ \\
\hline & Bentley & 宾利 & A \\
\hline & Renault & 雷诺 & A \\
\hline & REIZ & 锐志 & C \\
\hline & \begin{tabular}{|l|} 
Passat \\
\end{tabular} & 帕萨特 & $\mathrm{A}$ \\
\hline & Camry & 凯美瑞 & D \\
\hline & Prado & 普拉多 & D \\
\hline & \begin{tabular}{|l|} 
Corolla \\
\end{tabular} & 卡罗拉 & D \\
\hline & Lexus & 雷克萨斯 & D \\
\hline \multirow{10}{*}{$\begin{array}{l}\text { Literal translation } \\
\text { (10) }\end{array}$} & Bluebird & 蓝鸟 & A \\
\hline & Beetle & 甲壳虫 & B \\
\hline & Crown & 皇冠 & C \\
\hline & Regal & 君威 & C \\
\hline & Lotus & 莲花 & A \\
\hline & Golf & 高尔夫 & D \\
\hline & \begin{tabular}{|l|} 
Swift \\
\end{tabular} & 雨燕 & B \\
\hline & \begin{tabular}{|l|} 
Sunny \\
\end{tabular} & 阳光 & C \\
\hline & Landwind & 陆风 & B \\
\hline & Mustang & 野马 & B \\
\hline
\end{tabular}


(Table 1 continued)

\begin{tabular}{|c|c|c|c|}
\hline Translation methods & English name & Chinese name & Translation principle \\
\hline \multirow{17}{*}{$\begin{array}{l}\text { Combination of transliteration } \\
\text { and literal translation } \\
\text { (17) }\end{array}$} & Benz & 奔驰 & B \\
\hline & Transit & 全顺 & C \\
\hline & City & 思迪 & D \\
\hline & New Santafe & 新圣达菲 & D \\
\hline & Land Rover & 路虎 & B \\
\hline & \begin{tabular}{|l|} 
Citroen \\
\end{tabular} & 雪铁龙 & B \\
\hline & Jaquar & 捷豹 & B \\
\hline & Hummer & 悍马 & B \\
\hline & \begin{tabular}{|l} 
Legacy \\
\end{tabular} & 力狮 & B \\
\hline & Royaum & 荣御 & C \\
\hline & Fit & 飞度 & B \\
\hline & Jetta & 捷达 & B \\
\hline & Porsche & 保时捷 & B \\
\hline & \begin{tabular}{|l|} 
Opel \\
\end{tabular} & 欧宝 & C \\
\hline & Family & 福美来 & C \\
\hline & Tiguan & 途欢 & C \\
\hline & Touran & 途安 & C \\
\hline \multirow{7}{*}{$\begin{array}{l}\text { Free translation } \\
\text { (7) }\end{array}$} & BWM & 宝马 & C \\
\hline & Twingo & 丽人行 & C \\
\hline & LaCrosse & 君越 & C \\
\hline & Excelle & 凯越 & C \\
\hline & Accord & 雅阁 & C \\
\hline & \begin{tabular}{|l} 
Stream \\
\end{tabular} & 时韵 & C \\
\hline & Sagitar & 速腾 & B \\
\hline
\end{tabular}

Notes. A: Corporate Culture; B: Automobile Performance; C: Psychology of Target Addressee; D: others.

Table 1 is simplified into Table 2.

Table 2

Four Skopos Translation Methods

\begin{tabular}{lcclll}
\hline $\begin{array}{l}\text { Skopos translation } \\
\text { method }\end{array}$ & Transliteration & Literal translation & $\begin{array}{l}\text { Combination of transliteration and } \\
\text { literal translation }\end{array}$ & $\begin{array}{l}\text { Free } \\
\text { translation }\end{array}$ & Total \\
\hline A & & 2 & 0 & 0 & 21 \\
B & 19 & 4 & 9 & 1 & 14 \\
C & 0 & 3 & 6 & 6 & 16 \\
D & 1 & 1 & 2 & 0 & 7 \\
Total & 4 & 10 & 17 & 7 & 58 \\
\hline
\end{tabular}

Through the analysis, we can come up with the following three Skopos as translation principles.

Corporate culture. From Tables 1-2, we can say that the company usually adopt transliteration when it treats corporate culture as its Skopos. And the corporate culture is represented in the brand names named after corporate contributor, historical celebrity or legend.

Take “Audi” for instance, it is a kind of car produced by Volkswagen Company. First manufactured by German engineer August Horch (the founder of A. Horch \& Cie Automobile Company, established in 1899), it 
was named after Horch's name. In 1902, he moved his company to Zwickau in Saxony, and it was reorganized into a joint-stock company. In 1909, following a dispute with the members of the executive and supervisory boards, August Horch left the company and later established a second automobile manufacturing operation. Since he could not use his own name, which was a registered brand name, he chose a Latin translation instead: The German word "Horch” (meaning "Listen”) became “Audi”.

"Mazda" is the name of god-Afura Mazda that symbolizes the spirit of ancient civilizations with the meaning of wisdom, reason, and harmony. Owing to the pursuit of world peace, the admiration of Eastern and Western civilizations and the respect of a pioneer in the automotive industry, Mazda was born. What is more, "Mazda" and the pronunciation of the founder of Mazda—Matsuda Jujiro’s surname is homophonous.

Citroen "Elysee", is the perfect combination of French style and Chinese fashion. French "Elysee" means the "Paradise of Heaven”. Since the Third Republic in 1873, Elysee Palace has been the president of France. As a car name, Elysee is imbued with the French romantic style atmosphere.

Lotus is a masterpiece of the British gentleman Colin Chapman whose Lotus team has seven wins in F1 race since 1958, and creates a variety of excellent models. As a car fanatic, Chapman created brilliant achievements in both car-manufacturing and car racing.

Automobile performance. When the corporation attaches more importance to automobile performance, the translation method of automobile brand name tends to be combination of transliteration and literal translation. Sometimes literal translation is used.

The translation of Mercedes-Benz (Germany) is a typical representative. Mercédès is pseudonym of Emil Jellinek, the Austrian businessman, which is also the name of his daughter meaning "grace". At the beginning of 1900, Jellinek made an agreement with DMG (Daimler-Motoren-Gesellschaft) concerning sales of cars and engines and the decision was taken to use the Jellinek's pseudonym as a product name. So transliteration is the best choice when Mercedes is translated into Chinese. And “Benz” is translated into “奔驰”, which complies with the original English pronunciation, reflects the solemn elegance, and literally embodies the superior performance of the car-experiencing the feeling of gallop. As a matter of fact, “奔驰” is much more vivid than “平治” the Chinese name in Hong Kong.

“Porsche” and “Jetta” are translated into “保时捷” and “捷达” respectively which mean being fast and on time so that consumers who love these brands of cars doubled.

“Land Rover” (路虎), “Citroen” (雪铁龙), “Hummer” (悍马), and “Legacy” (力狮) all the translated names are on the remodeling in Chinese characters, selecting "tiger, dragon, horse, lion” so as to demonstrate the speed and passion to meet the traditional Chinese culture.

Swift is very small agreeable car, pleasing most consumers. Its most loyal supporters are those young boys and girls who seek fashion with rounded front line full, waist smooth flowing, headlight cute, and flat roof full of classic-style atmosphere. So the literal translation into “雨燕” interprets well the good-looking and performance of the car. So does “Beetle” (甲壳虫). The Beatles mentioned, consumers will think of many unique advantages immediately, such as cheap, sturdy, practical, and good handling.

Psychology of target addressee. Due to cultural and linguistic differences between languages, a successful translation in one nation does not guarantee its success in another nation. So sometimes psychology of target 
addressee plays a great role in the translation. In addition, under this circumstance, combination of transliteration and literal translation and free translation are mainly used.

BMW stands for Bavarian Motor Works - the acronym in German, which is only product information, no cultural meaning. If adopted literal translation, it is too long, neither succinct nor any sense of beauty. If retained as "BMW", it is not consistent with the Chinese language habits, and does not play the role of language to convey information. The first letter “ $B$ ” reminds us the consonant sounds [b], to create a “宝” that is valuable, rare, reflecting the high value of the car; the second letter " $M$ ", how to associate it with the car up? Before the invention of the car, horse is the only means of transportation. So the “BMW” is the “宝马”, which has been a status symbol.

“Transit” is translated into “全顺” which has no relation with the original meaning. And in Chinese, “全顺” means "safe and sound all the way", meeting the psychological need of safe.

In the framework of Skopostheorie, one of the most important factors determining the purpose of a translation is the addressee, who is the intended receiver or audience of the target-text with their culture-specific world knowledge, their expectations, and their communicative needs.

Bovee and William (1989, p. 12) pointed out that: In advertising, of which brand name translation is an important branch, the target audience is generally defined as the group of individuals to whom the advertising message is directed, or in other words, those who will buy the product for their own or someone else's use. In this sense, the target addressee can be regarded as the consumer or potential consumer in automobile brand name translation. Since the target addressees are different, translation strategies and methods adopted should also be varied. To achieve the purpose of informing the target addressees and persuade them to make a purchase, the translator should take into full consideration such aspects as age, gender, financial situation, education background, and profession of the target addressees.

\section{Conclusions}

Brand name translation, as an intercultural commercial translation, should be subject to the ultimate purpose of advertisement - to promote sales on a competitive market. So long as it appeals to the consumers and makes a good impression on them, and evokes the consumers to make a purchase, it can be regarded as a good brand name. Brand name translation is consumer-oriented. A brand name is restricted by the Skopos of translation and many factors involving the target addressee. Only within the framework of the functionalist theory are we free to choose the best translation strategy. Skopostheorie, a theory of purposeful action, claims that the prime principle determining any translation process is the purpose (Skopos) of the overall translation action. Thus the top-ranking rule for any translation is the "Skopos rule", which says that a translational action is determined by its Skopos, that is, "the end justifies the means".

Based on the analysis of the naming and functions of brand names, three purposes should be born in mind in translating automobile brand names. In light of the Skopotheorie, several important factors are taken into consideration when doing automobile brand name translation. Consequently, here are suggested four translation methods and three translation Skopos analyzed with detailed examples. Of course, compared with the huge quantity of automobile brand names in the world, the translation of the examples listed here is only a small part. Efforts should be made to improve the practical guidance of Skopostheorie to automobile brand name translation 
in a broad range, such as brand advertisement, brand slogans and signs, and so on. The principles and strategies proposed in this paper should be regarded as suggestions rather than absolute rules, as they have to be tested and modified in translation practice.

\section{References}

Bovee, L. C., \& William, F. A. (1989). Contemporary advertising (3rd ed.). Boston: Richard D. Irwin, Inc..

CHEN, F. Y. (2004). On functionalist theory in brand name translation in the light of consumer psychology. Chengdu: Si Chuan Normal University.

Hankinson, G., \& Cowking, P. (1993). Branding in action: Cases and strategies for profitable brand management. London: McGraw-Hill.

LIANG, G. T. (1998). On translation of trademark word. Chinese Science \& Technology Translators Journal, (2), 22-24.

Munday, J. (2001). Approaches to translation. Shanghai: Shanghai Foreign Language Education Press.

Newmark, P. (2004). A text book of translation. Shanghai: Shanghai Foreign Language Education Press.

Nida, E. A. (2001). Language and culture and translation. Shanghai: Shanghai Foreign Language Education Press.

Nord, C. (2001). Translating as a purposeful activity. Shanghai: Shanghai Foreign Language Education Press.

Reiss, K. (2004). Translation criticism: The potentials \& limitations. Shanghai: Shanghai Foreign Language Education Press.

Vermeer, H. J. (1989). Skopos and commission in transitional action. In L.Venuti (Ed.), The translation study reader. London: Routledge.

WU, J., \& CAO, W. (2005). Trademark language. Shanghai: Chinese Dictionary Press.

YAN, F. (1984). Evolution and ethics. Collection of translation studies papers. Beijing: Foreign Language Teaching and Research Press. 